\title{
INVESTIGATION OF AMOEBICIDAL POTENTIAL OF ARACHIS HYPOGAEA L. PERICARP ON CYSTS OF ACANTHAMOEBA ASTRONYXIS T7 GENOTYPE
}

RANIA M SARHAN ${ }^{1 *}$, HAYAM M EZZ ELDIN ${ }^{1}$ AND MONA H HETTA ${ }^{2}$

Department of Parasitology ${ }^{1}$, Faculty of Medicine, Ain Shams University, Cairo

11566, Department of Pharmacognosy², Faculty of Pharmacy, Fayoum University,

Fayoum, Egypt. ( ${ }^{*}$ Correspondence: E-mail: raniasarhan99@gmail.com)

\section{Abstract}

Acanthamoeba is an opportunistic pathogen causing keratitis and fatal encephalitis. Early diagnosis, followed by intense treatment using a drugs mixture is a necessity for effective therapy. Many natural compounds have proved lethal effects, yet the search for original natural amebicidal agents is still of current concern.

This study investigated the acanthamoebicidal effect of A. hypogaea L. pericarp; total ethanol extract and its successive fractions, n-hexane, dichloro-methane, ethyl acetate, and methanol as well as resveratrol. Acanthamoebae were isolated and cultivated on E. coli seeded nonnutrient agar, genotyped, and the in vitro acanthamoebicidal potentials of different concentrations of A. hypogaea L. pericarp; total extract ethanol and its successive fractions and resveratrol compound was investgated on cysts of A. astronyxis T7 genotype.

The results showed variable degrees of lethal potentials were obtained by all examined $A$. hypogaea $L$. pericarp ethanol extract and its successive fractions, with the highest mean of non-viable cysts on the first and the second days of the study by total ethanol extract followed by the methanol fraction. On the third day of the study $n$-hexane and ethyl acetate gave the highest mean of non-viable cysts. Resveratrol showed the lowest mean of non-viable cysts count all through the study duration. Significantly higher difference was observed between all examined A. hypogaea $L$. pericarp extract and fractions and chlorohexidine, except for resveratrol compound the difference was found to be non-significant.

Keywords: Acanthamoeba, Arachis hypogaea L., Amoebicidal, Resveratrol, Amoebic keratitis, peanuts

\section{Introduction}

Acanthamoeba is a facultative pathogen, found naturally in soil and fresh water, causing keratitis or granulomatous amoebic encephalitis. It can exist in the pathogenic trophozoite or encysted form in times of physiological stress and become metabolically dormant. Several species of Acanthamoeba have been associated with human infections causing severe keratitis; $A$. astronyxis, A. castellanii, A. culbertsoni, A. polyphaga, A. hatchetti, A. rhysodes, A. lugdunensis, A. palestinensis, A. griffini, and A. quina (Siddiqui and Khan, 2012: MarcianoCabral and Cabral, 2003). The case numbers of pathogenicity towards the eye have risen (Clarke et al, 2012). Acanthamoeba borne keratitis comprises of the destruction of the epithelial barrier, invasion of the stroma, keratocyte reduction, triggering an intense inflammatory response and eventually stromal necrosis (Garner, 1993; Perez-Santonja et al, 2003). Inadequate asepsis in contact lens wearers due to the use of multipurpose lens solution leads to a contamination by bacteria and fungi and produces a favorable culture medium for the growth of this protozoan (Jasim et al, 2012). Other major risk factors are associated with eye trauma and poor water supply (Obeid et al, 2003).

Treatment is challenging and consists of an hourly topical application of a more than one drug including polyhexamethylene biguanide or chlorhexidine digluconate with propamidine isethionate. Additionally chloramphenicol or neomycin is also given to prevent concomitant bacterial infection (Perez-Santonja et al, 2003). Despite the lengthy treatment, recurrence is highly encountered (Ficker et al, 1990). 
The most vital factors affecting prognosis include the severity of the condition at presentation and time gap between the onset of symptoms and the start of effective therapy, that was reached after the elimination of viable cysts (Muller et al, 2012). The study of plants used by traditional medicine is a strategy for finding dynamic substitute treatment (Brantner and Grein, 1994). Many natural compounds have showed antiparasitic and anti-amoebic effects (Derda, 2009; Degerli, 2011) yet the search for novel natural amoebicidal agents is still of current concern (Kayser et al, 2003: Roongruangchai et al, 2010).

Arachis hypogaea L. (Peanut), family Leguminosae is distributed in the tropics and moderate regions. Peanut hulls though considered as waste products of no nutritional values (Geetha et al, 2013), it exert numerous curative potentials such as antioxidative, antibacterial, antifungal and anti-inflammatory activities (Sobolev et al, 2011), as well as anti-Leishmanial activity (Yazaki et al, 2009).

Resveratrol, an important component in peanut showed in vivo inhibition to TNF-R and IL- 6 released from macrophages, thereby suppressing macrophage-CM-induced inflammatory response in adipocytes (Kang et al, 2010). Also it was proved to have an outstanding anti-viral, anti-inflammatory and anti-cancer effect (Geetha et al, 2013). also the content of resveratrol in peanut pericarp showed inhibitory activity of carbohydrate hydrolyzing enzymes (Hetta et al, 2014).

The ethanol extract of A. hypogaea L. shell proved a remarkable cysticidal effect and could be considered a new natural amoebicidal source against the Acanthamoeba castellanii cysts, showing more potent effect than the conventional chlorhexidine (Elsayed et al, 2011).

The present study aimed to investigate the in vitro acanthamoebicidal effect of $A$. hypogaea $L$. pericarp; total ethanol extract and its successive fractions ( $n$-hexane, dichloro- methane, ethyl acetate, and methanol) as well as resveratrol compound, against Acanthamoeba asstronyxis (T7) genotype, for further testing of its acanthamoebicidal activity and to correlate between the chemical constituents of A. hypogaea $L$. pericarp and its biological activity in the presence of chlorohexidine as reference drug.

\section{Material and Methods \\ Phytochemical study:}

Plant material: The fruits of Arachis hypogaea L. (peanuts) were collected from ElBehera Governorate on the year 2014. The plant was kindly identified by Mrs. Therese Labib senior botanist in Eln Garden Egypt. The plant was authenticated and a voucher sample no. BSP25 was deposited in Department of Pharmacognosy, Faculty of Pharmacy, Fayoum University, Egypt. The pericarps (hulls) (Fig. 1) were separated from the seeds manually and pulverized and stored in glass containers for phytochemical and biological studies.

Chemicals: All the solvents used were of analytical grade, Sigma Aldrich Germany.

Preparation of extracts: The powdered pericarp of Arachis hypogaea L. was extracted by maceration on cold with $70 \%$ ethanot till exhaustion. The combined extracts were collected, filtered and concentrated under reduced pressure and kept as the first tested sample of total ethanol extract. Part of the residue was shacked with water and successively fractionated with solvents in increasing polarity using a separating funnel to prepare the four extractives ( $n$ - hexane, dichloromethane, ethyl acetate and methanol). They were concentrated and the residue left for each was weighed, kept in an amber glass container, and stored in a refrigerator for further studies. Phytochemical screening was carried out with the extractives for testing the chemical components by reactions specific to the class of the secondary metabolites present as terpenoids and/or steroids, alkaloids, flavonoids, coumarins, and tannins (Wagner and Bladt, 1996).

The standard resveratrol extract of Arachis 
hypogaea $L$. pericarp was kindly supplied by Dr. Muhammed Ilias, School of Pharmacy, University of Mississippi, USA (of $99.8 \%$ purity). It was prepared as $5 \mathrm{mg} / \mathrm{ml}$ and stored in aliquots at $-20^{\circ} \mathrm{C}$ to be used within six months.

Biological study: Acanthamoebae cultures: Samples of corneal scraps were collected from patients suffering from keratitis attending the corneal outpatient clinic of the Research Institute of Ophthalmology, Giza, Egypt.

Acanthamoeba separation was implemented in the Diagnostic and Research Laboratory of Parasitic Diseases, Parasitology Department, Faculty of Medicine, Ain Shams University, Cairo, Egypt. By direct inoculation of the specimens onto the surface of $1.5 \%$ non-nutrient agar (NNA) plates seeded with Escherichia coli $(E$. coli) and incubated in a humidified chamber at $30^{\circ} \mathrm{C}$ (Init et al, 2010). The existence of Acanthamoeba could be tracked by the clear tracks on the $E$. coli lawn NNA produced by the feeding trophozoites. Examination of the agar plate for the amoebic growth was carried out daily for up to 7 days with light and inverted microscopes. Subcultures were carried out after 2 weeks from positive cultures with confirmed amoebic growth. The plates were incubated in humidified chambers at $30^{\circ} \mathrm{C}$ and examined after $24 \mathrm{~h}$. Performing subculture several times enabled the isolation of Acanthamoeba. Cysts were collected from 3week cultures. The agar surfaces were flooded with $5 \mathrm{ml}$ of phosphate-buffered saline (PBS) and were gently scraped with an inoculating loop. Cysts were then harvested by centrifugation at $350 \times \mathrm{g}$ for $10 \mathrm{~min}$. The supernatant was aspirated, and the sediment was washed twice in PBS in order to exclude most of the bacteria. Cysts in the resulting suspension were counted with a hemocytometer, and the count was standardized to be $25 \times 10^{4} / \mathrm{ml}$ (Perrine et al. 1995).

Molecular characterization, Sequencing and Genotype identification: It was carried out at Ain Shams University Genetic Engi- neering Research Services. Cysts were harvested (Gatti et al, 2010). The sediment was stored at $-20^{\circ} \mathrm{C}$ for DNA extraction using "EasyQuick DNA extraction kit by Genomix" and further polymerase chain reaction according to Schroeder et al. (2001). PCR products from Acanthamoeba keratitis isolates were purified using the AxyPrep PCR Clean-up kit (AXYGEN BiosciencesUSA) and sequenced using an automated fluorescence sequencing system (Applied Biosystems 3730XL genetic DNA analyzer) (Chen, 1994). Phylogenetic analysis of the obtained sequences was carried out using software program "Molecular and Evolutionary Genetics Analysis" (MEGA) (version 6.0). Genotype identification was based on sequence analysis of diagnostic fragment 3 (DF3) regions (Booton et al, 2002) by comparison to the available DNA sequences in Genbank and Acanthamoeba astronyxis T7 genotype was revealed.

Amoebicidal test: Acanthamoeba astronyxis T7 genotype was incubated with concentrations of $(100,50,25,12.5$ and 6.25 $\mathrm{mg} / \mathrm{ml}$ ) for each of; ethanol extract and fractions; $n$ - hexane, dichloro-methane, ethyl acetate and methanol and concentrations of $(0.2,0.1,0.05,0.025$ and $0.0125 \mathrm{mg} / \mathrm{ml})$ for resveratrol, adjusted by dilution in dimethyl sulfoxide 1\% (DMSO) (Ezz Eldin and Sarhan 2014). These concentrations were chosen after several initial trials guided by previous literature (Elsayed et al, 2011, Geetha et al, 2013, Kim et al, 2013).

One hundred microliters of the calibrated cyst suspension $\left(2.5 \times 10^{5} / \mathrm{ml}\right)$ were inoculated into each well of a 96-well plate, left for 30 min to avoid disturbance of the adherence of amoebae onto the wells' surface. PBS solution was removed, and $100 \mu$ of each concentration of the samples was added into the wells. The plate was sealed and incubated at $30^{\circ} \mathrm{C}$ for incubation periods of $(24,48, \& 72$ hrs). Negative control containing the parasite in PBS and drug control including parasite in $0.02 \%$ chlorhexidine gluconate (prepared from a solution $20 \%$ in $\mathrm{H} 2 \mathrm{O}$ CHX, C- 
9394; Sigma) were used. The effect of DMSO was excluded by using a well containing the parasite plus $1 \%$ DMSO. Trials were performed in triplicates. After each incubation period, $100 \mu \mathrm{l}$, from each test and control wells, were transferred into $100 \mu \mathrm{l}$ of $0.3 \%$ basic methylene blue media for counting the unstained (viable) and stained (nonviable) cysts by hemocytometer, $10 \mathrm{~min}$ after stain addition. Cultures containing nonviable cysts were re- inoculated onto NNAE.coli plate, incubated at $30^{\circ} \mathrm{C}$ for an additional $72 \mathrm{hrs}$, and examined to detect any viable cysts (Polat et al. 2008).

Evaluation of the drug efficacy was done by: 1 - Counting the number of cysts using the hemocytometer and methylene blue stain after each period of incubation, 2- Calculation of the percent of growth inhibition according to the equation (Palmas et al. 1984); Percent of growth reduction $=\mathrm{a}-\mathrm{b} / \mathrm{ax} 100$. Where, $a$ is the mean number of cysts in control cultures and $b$ is the mean number of cysts in drug-treated cultures

Data management and analysis: The collected data was revised, coded, tabulated and introduced to a PC using Statistical package for Social Science (SPSS 15.0.1 for windows; SPSS Inc, Chicago, IL, 2001).

Descriptive statistics: 1- Mean standard deviation $( \pm \mathrm{SD})$ and range for parametric numerical data, 2- Frequency and percentage of non-numerical data.

Analytical statistics: 1-ANOVA test was used to assess the statistical significance of the difference between more than two study group means, 2- Post Hoc Test is used for comparisons of all possible pairs of group means, 3- One-Sample T Test was used to test whether the mean of a variable differs from a specified constant, 4- Repeated measures ANOVA was used to test the statistical significance of the difference of a numerical variable with measured more than two times for the same study group. P- value: level of significance; $\mathrm{P}>0.05$ : Non sig- nificant (NS). $\mathrm{P}<0.05$ : Significant $(\mathrm{S})$ and $\mathrm{P}<0.001$ : Highly significant (HS).

Ethical consideration: An informed consent was taken from the patients suffering keratitis after explaining the aim of the study. The study was approved by the research Ethics Committee, Faculty of Medicine, Ain Shams University.

\section{Results}

All tested Arachis hypogaea L. pericarp extracts to have a promising acanthamoebicidal effect in varying degrees. The highest mean for non-viable percentage of parasites was reached by total ethanol extract in days one and two of the experiment followed by $n$ hexane fraction in day three. The highest lethal effect from ethanol extract was obtained in day two, $n$ hexane fraction in day three, dichloro-methane fraction in day 2, ethyl acetate fraction in day 3, methanol fraction and resveratrol in day two. There was a highly significant difference between each individual drug to one another in each day of the study duration (Tab. 1, Fig. 2).

Along the duration of study, total ethanol extract, showed a highly significant difference between its five used concentrations as regard non-viable parasite percentage at days $2 \& 3$, and a non-significant difference at day 1 . At day 1 the concentrations; $\mathrm{c} 1$ and c2 gave the highest non-viable parasite percentage, at day 2 concentration $\mathrm{c} 3$ and at day 3 concentration $\mathrm{c} 4$ was the most potent. Regarding $n$ - hexane, there was a highly significant difference between its five used concentrations as regard non-viable parasite percentage at days 1 and 3 while a nonsignificant difference was detected at day 2 . Concentration 4 gave the highest non-viable parasite percentage at days $1 \& 2$, while at day 3 c5 showed the highest percentage of growth inhibition. Dichloro-methane showed a highly significant difference between its five used concentrations at days 1 and 2, and significant difference at day 3 . At day $1 \mathrm{c} 4$ was the most potent, at 
Table 1: Comparison of the amoebicidal effect of Arachis hypogaea L. pericarp ethanol extract and its successive fractions; $n$-hexane, dichloromethane, ethyl acetate, methanol and resveratrol compound along duration of study on Acanthamoeba astronyxis cysts.

\begin{tabular}{|c|c|c|c|c|c|c|c|c|}
\hline Drug & Total Ethanol & $n$-hexane & Dichloro-methane & Ethyl acetate & Methanol & Resveratrol & \multirow{2}{*}{ P } \\
\hline Days & \multicolumn{7}{|c|}{ Mean \pm SD } & \\
\hline Day 1 & $132.9 \pm 27.46$ & $60.5 \pm 48.55$ & $115.8 \pm 53.61$ & $31.7 \pm 20.74$ & $84.1 \pm 59.42$ & $27.5 \pm 11.29$ & $.0001^{* *}$ \\
\hline Dav 2 & $176.0 \pm 72.22$ & $78.9 \pm 27.25$ & $125.1 \pm 56.24$ & $134.4 \pm 68.90$ & $171.5 \pm 40.13$ & $51.7 \pm 22.24$ & $.0001^{* *}$ \\
\hline Dav 3 & $118.7 \pm 83.37$ & $211.7 \pm 51.29$ & $83.3 \pm 52.55$ & $171.5 \pm 44.29$ & $97.1 \pm 51.11$ & $49.4 \pm 44.18$ & $.0001^{* *}$ \\
\hline
\end{tabular}
SD: Standard deviation, P value: Level of significance, **Highly significant $(<0.001)$

Table 2: Percentages of growth inhibition by different concentrations of Arachis hypogaea L. pericarp ethanol extract and successive fractions; $n$-hexane, dichloromethane, ethyl acetate, methanol and resveratrol compound along duration of study on Acanthamoeba astronyxis cysts.

\begin{tabular}{|c|c|c|c|c|c|c|c|}
\hline & \multicolumn{2}{|c|}{ Day 1} & \multicolumn{2}{|c|}{ Day 2} & \multicolumn{2}{|c|}{ Day 3} \\
\hline & & $\begin{array}{c}\text { Growth } \\
\text { inhibition\% }\end{array}$ & Mean \pm SD & $\begin{array}{c}\text { Growth } \\
\text { inhibition\% }\end{array}$ & Mean \pm SD & $\begin{array}{c}\text { Growth } \\
\text { inhibition\% }\end{array}$ & Mean \pm SD \\
\hline \multirow{6}{*}{$\begin{array}{c}\text { Total } \\
\text { Ethanol }\end{array}$} & $\mathrm{C} 1$ & 53.79 & $156 \pm 8.49$ & $74.14 \%$ & $215 \pm 21.21$ & 73.21 & $205 \pm 7.07$ \\
\hline & $\mathrm{C} 2$ & 53.79 & $156 \pm 8.49$ & $31.90 \%$ & $92.5 \pm 3.54$ & 3.04 & $8.5 \pm 0.71$ \\
\hline & $\mathrm{C} 3$ & 44.83 & $130 \pm 42.43$ & $99.14 \%$ & $287.5 \pm 10.61$ & 33.75 & $94.5 \pm 6.36$ \\
\hline & $\mathrm{C} 4$ & 40.52 & $117.5 \pm 24.75$ & $49.14 \%$ & $142.5 \pm 3.54$ & 75.89 & $212.5 \pm 17.68$ \\
\hline & $\mathrm{C} 5$ & 36.21 & $105 \pm 7.07$ & $49.14 \%$ & $142.5 \pm 3.54$ & 26.07 & $73 \pm 4.24$ \\
\hline & $\mathrm{P}$ & \multicolumn{2}{|c|}{0.232} & \multicolumn{2}{|c|}{$0.0001 * *$} & \multicolumn{2}{|c|}{$0.0001 * *$} \\
\hline \multirow{6}{*}{$n$-hexane } & $\mathrm{C} 1$ & 19.31 & $56 \pm 8.49$ & $32.24 \%$ & $93.5 \pm 4.95$ & 61.25 & $171.5 \pm 2.12$ \\
\hline & $\mathrm{C} 2$ & 18.28 & $53 \pm 4.24$ & $12.59 \%$ & $36.5 \pm 0.71$ & 92.32 & $258.5 \pm 58.69$ \\
\hline & $\mathrm{C} 3$ & 3.10 & $9 \pm 0$ & $23.45 \%$ & $68 \pm 1.41$ & 55.00 & $154 \pm 5.66$ \\
\hline & $\mathrm{C} 4$ & 50.34 & $146 \pm 8.49$ & $38.97 \%$ & $113 \pm 1.41$ & 74.82 & $209.5 \pm 13.44$ \\
\hline & C5 & 13.28 & $38.5 \pm 2.12$ & $28.79 \%$ & $83.5 \pm 4.95$ & 94.64 & $265 \pm 7.07$ \\
\hline & $\mathrm{P}$ & \multicolumn{2}{|c|}{$0.0001 * *$} & \multicolumn{2}{|c|}{0.246} & \multicolumn{2}{|c|}{$0.0001 * *$} \\
\hline \multirow{5}{*}{$\begin{array}{l}\text { Dichloro- } \\
\text { methane }\end{array}$} & $\mathrm{C} 1$ & 9.14 & $26.5 \pm 9.19$ & $62.07 \%$ & $180 \pm 14.14$ & 61.07 & $171 \pm 1.41$ \\
\hline & $\mathrm{C} 2$ & 42.24 & $122.5 \pm 3.54$ & $26.72 \%$ & $77.5 \pm 0.71$ & 36.96 & $103.5 \pm 4.95$ \\
\hline & $\mathrm{C} 3$ & 37.07 & 107.510 .61 & $22.24 \%$ & $64.5 \pm 3.54$ & 16.79 & $47 \pm 0$ \\
\hline & $\mathrm{C} 4$ & 61.215 & 177.510 .61 & $37.59 \%$ & $109 \pm 12.73$ & 22.14 & $62 \pm 2.83$ \\
\hline & $\mathrm{C} 5$ & 50.00 & $145 \pm 7.07$ & $67.07 \%$ & $194.5 \pm 6.36$ & 11.79 & $33 \pm 4.24$ \\
\hline & $\mathrm{P}$ & \multicolumn{2}{|c|}{$0.0001 * *$} & \multicolumn{2}{|c|}{$0.0001 * *$} & \multicolumn{2}{|c|}{$0.03 *$} \\
\hline \multirow{5}{*}{$\begin{array}{l}\text { Ethyl } \\
\text { acetate }\end{array}$} & $\begin{array}{l}\mathrm{C} 1 \\
\mathrm{C} 2\end{array}$ & $\begin{array}{l}0.11 \\
2.07\end{array}$ & $\frac{265 \pm 778}{6 \pm 7.07}$ & $\frac{200 n \%}{19.48 \%}$ & $\begin{array}{c}58 \pm 707 \\
56.5 \pm 9.19\end{array}$ & $\frac{7500}{50.89}$ & $\frac{210+1414}{142.5 \pm 3.54}$ \\
\hline & $\mathrm{C} 3$ & 7.41 & $21.5 \pm 2.12$ & $70.69 \%$ & $205 \pm 7.07$ & 41.96 & $117.5 \pm 24.75$ \\
\hline & $\mathrm{C} 4$ & 21.72 & $63 \pm 4.24$ & $67.76 \%$ & $196.5 \pm 9.19$ & 58.93 & $165 \pm 7.07$ \\
\hline & $\mathrm{C} 5$ & 14.31 & $41.5 \pm 2.12$ & $53.79 \%$ & $156 \pm 5.66$ & 79.46 & $222.5 \pm 31.82$ \\
\hline & $\mathrm{P}$ & \multicolumn{2}{|c|}{$0.0001 * *$} & \multicolumn{2}{|c|}{$0.0001 * *$} & \multicolumn{2}{|c|}{$0.0001 * *$} \\
\hline \multirow{6}{*}{ Methanol } & $\mathrm{C} 1$ & 14.66 & $42.5 \pm 3.54$ & $65.34 \%$ & $189.5 \pm 0.71$ & 51.07 & $143 \pm 4.24$ \\
\hline & $\mathrm{C} 2$ & 9.66 & $28 \pm 2.83$ & $42.93 \%$ & $124.5 \pm 6.36$ & 16.07 & $45 \pm 0$ \\
\hline & $\mathrm{C} 3$ & 34.66 & $100.5 \pm 0.71$ & $71.90 \%$ & $208.5 \pm 12.02$ & 16.61 & $46.5 \pm 2.12$ \\
\hline & $\mathrm{C} 4$ & 22.07 & $64 \pm 5.66$ & $52.59 \%$ & $152.5 \pm 74.25$ & 31.79 & $89 \pm 12.73$ \\
\hline & $\mathrm{C} 5$ & 63.97 & $185.5 \pm 7.78$ & $62.93 \%$ & $182.5 \pm 4.95$ & 57.86 & $162 \pm 2.83$ \\
\hline & $\mathrm{P}$ & \multicolumn{2}{|c|}{$0.0001 * *$} & \multicolumn{2}{|c|}{$0.0001 * *$} & \multicolumn{2}{|c|}{$0.012 *$} \\
\hline \multirow{6}{*}{ Resveratrol } & $\mathrm{C} 1$ & 11.03 & $32 \pm 2.83$ & $26.38 \%$ & $76.5 \pm 9.19$ & 12.68 & $35.5 \pm 2.12$ \\
\hline & $\mathrm{C} 2$ & 12.76 & $37 \pm 4.24$ & $10.86 \%$ & $31.5 \pm 2.12$ & 8.04 & $22.5 \pm 0.71$ \\
\hline & $\mathrm{C} 3$ & 9.66 & $28 \pm 2.83$ & $14.66 \%$ & $42.5 \pm 3.54$ & 16.96 & $47.5 \pm 3.54$ \\
\hline & $\mathrm{C} 4$ & 2.59 & $7.5 \pm 3.54$ & $26.38 \%$ & $76.5 \pm 9.19$ & 45.18 & $126.5 \pm 37.48$ \\
\hline & $\mathrm{C} 5$ & 11.38 & $33 \pm 4.24$ & $10.86 \%$ & $31.5 \pm 2.12$ & 5.36 & $15 \pm 7.07$ \\
\hline & $\mathrm{P}$ & \multicolumn{2}{|c|}{$0.003 * *$} & \multicolumn{2}{|c|}{$0.001 * *$} & & $7 * *$ \\
\hline
\end{tabular}

C: concentration; SD: standard deviation, (C1-C5) refers to $(100,50,25,12.5$ and $6.25 \mathrm{mg} / \mathrm{ml})$ for each of; total ethanol, $n$-hexane, dichloromethane, ethyl acetate and methanol and $(0.2,0.1,0.05,0.025$ and $0.0125 \mathrm{mg} / \mathrm{ml})$ for Resveratrol, P value : Level of significance, **Highly significant $(<0.001)$, *Significant

day 2 c5 was the most potent while at day 3 c1 gave the highest outcome. Ethyl acetate showed a highly significant difference between its five used concentrations as regard lethal potential along the whole duration. At day $1 \mathrm{c} 4$ was the most potent, at day $2 \mathrm{c} 3$ gave the highest result and at day 3 it was c5. Methanol revealed a highly significant difference between its five used concentrations regarding non-viable parasite percentage at days 1 and 2 and a significant difference at day 3. At day $1 \mathrm{c5}$ gave the highest result, at day 2 it was c3 and at day 3, c5. Resveratrol, showed a highly significant dif- 
ference between its five used concentrations. At day $1 \mathrm{c} 5$ was the most potent, at day 2, c1 and $\mathrm{c} 4$ showed the highest lethal effect and at day 3, c4 (Tab. 2).

To summarize, the total ethanol extract showed the highest mean of non-viable cysts, followed by the methanol fraction, ethyl acetate, dichloromethane, $n$-hexane and finally resveratrol regarding accumulative effect on second day (Fig. 2).

As regard the mean of non-viable count a significantly higher difference was found between total ethanol extract, methanol fraction and dichloro-methane fraction along the whole duration of the study as compared to chlorohexidine, that difference was revealed as well by $n$-hexane on day 3 and ethyl acetate on day 1 , while a non-significant difference was found between resveratrol when compared to chlorohexidine along the whole duration of the study as well as $n$-hexane in first and second days and ethyl acetate in first day (Tab. 3). There was a highly significant difference when comparing the amoebicidal effect of the tested drugs to the parasite control.

\section{Discussion}

Acanthamoeba keratitis is a severe sight threatening infection which if not diagnosed early and treated aggressively may finally lead to loss of vision (Marciano-Cabral and Cabral 2003). Several substances obtained from plants have been considered for Acanthamoebacidal activity, and have proven to be more effective than the commercially utilized drugs (Polat et al, 2007, 2008: Goze et $a l, 2009)$. Antiparasitic properties of many new medicinal plant components have been identified with their surprising efficacy and selectivity such as plant-derived alkaloids, terpenes, and phenolics (Kayser et al, 2003).

The peanut or groundnut Arachis hypogaea has variable pharmacological activities against; bacteria, fungi, viruses, antioxidant, anticancer, antihypertensive, neuroprotective, antimutagenic, antiproliferative, antiinflammatory (Geetha et al, 2013) and potent anti acanthamoebic effect (Elsayed et al,
2011). The cysticidal effect of A. hypogaea $L$. was attributed to quercetin, plant derived flavonoids which represent a major component responsible for its biological actions (Wang et al, 2008) in inhibiting DNA synthesis and arresting cell cycle leading to apoptosis (Koide et al, 2002). The isolation of alkaloids and flavonoids has been reported from ethanol extract of $A$. hypogaea $L$. which may contribute to their cysticidal activity (Berkov et al, 2004; Ishita et al, 2004; Yazaki et al, 2009).

In the study, total ethanol extract, and its successive fractions; $n$ - hexane, dichloromethane, ethyl acetate, methanol and resveratrol were comparatively evaluated. Counting of Acanthamoebae was done using the classical hemocytometer method which has shown valid outcomes with absence of subjectivity compared to other colorimetric methods and viable cell counts which were proved strain-dependent leading in some cases to an overestimation of the real situation of viable cells (Buck and Rosenthal, 1996; Heredero-Bermejo et al, 2013).

All tested extracts showed a curve with a peak on second day, with total ethanol extract showing the highest mean of nonviable cysts, followed by the methanol fraction, ethyl acetate, dichloro-methane, $n$ hexane and finally resveratrol. unlike $n$ hexane and ethyl acetate which showed a different curve pattern, with a peak of action along accumulation on the third day which needs further study regarding accumulative effect. The difference in the lethal potential of each used dose highlighted a guide for the range of the best concentration of each fraction to be utilized and the period and outcome it will give along accumulation.

The study revealed total ethanol extract to be the most potent. This was approved by recent studies that demonstrated selected alcohol plant crude extracts containing phenolic to exhibit inhibitory effects on biological properties of Acanthamoeba in vitro (Duh and Yen, 1997; Shoaib et al, 2013). 
Phenolic compounds have shown to demonstrate powerful antioxidant properties (Pietta 2000). These phenolic compounds and most other reported bioactive compounds are generally soluble in polar solvents, such as ethanol (Houghton et al, 1998). Ethanol and methanol fractions were greater in total phenolic compounds, the ethanol extracts for each plant tissue resulted in higher antioxidant activity than other extraction solvents as $n$-hexane, dichloromethane and ethyl acetate, this antioxidant activity is related to the carotenoids and flavonoids contained within the plant to which the lethal effect may be assigned (Nepote et al, 2002).

The ethanol fraction of A. hypogaea $L$., hulls previously showed a remarkable inhibitory effect on growth of A. castellanii cysts (El-Sayed et al, 2011). In accordance to this study that proved prominent efficacy of the total ethanol extract and the methanol fraction from A. hypogaea L., hulls. The effect of methanol may have triggered the effect of its parent total ethanol in a synergistic way.

Studies recommended evaluation antiAcanthamoeba effects of resveratrol based on the percent of inhibition of $23 \%$ and selective toxicity on $A$. castellanii but not the brain endothelial cells (Aqeel et al, 2012). The percent was comparable to that obtained by our study but still lower that obtained by all of the examined extract and fractions.

All the used preparations of A. hypogaea L. pericarp proved potent in vitro amoebicidal activity on A. astronyxis T7 cysts even beyond the potentials of the commercially used drug "chlorohexidine", suggesting that they could be counted as new a natural agents candidate with special regards to synergetic effect of different constituents in total ethanol extract which added to its potency.

\section{Conclusion}

The study highlighted a guide for the ranges of concentrations to be used and the period and outcome $A$. hypogaea $L$. pericarp preparations will give along accumulation. All the used preparations proved in vitro amoebicidal activity and could be regarded as new natural agents candi- date with special regards to the synergetic effect of different elements in total ethanol extract which added to its potency.

\section{Acknowledgement}

The authors would like to acknowledge Professor Dr. Muhammed Ilias, School of Pharmacy, University of Mississippi, USA for offering resveratrol.

\section{References}

Aqeel, Y, Iqbal, J, Siddiqui, R, Gilani, AH, Khan, AN, 2012: Anti-Acanthamoebic properties of resveratrol and demethoxycurcumin. Exp. Parasitol. 132:519-23.

Berkov, S, Evstatieva, L, Popov, S, 2004: Alkaloids in Bulgarian Pancratium maritimum L. Z. Naturforsch C 59, 1/2:65-9.

Booton, GC, Kelly, DJ, Chu, YW, Seal, DV, et $a l$, 2002: $18 \mathrm{~S}$ ribosomal DNA typing and tracking of Acanthamoeba species isolates from corneal scrape specimens, contact lenses, lens cases, and home water supplies of Acanthamoeba keratitis patients in Hong Kong. J. Clin. Microbiol. 40:1621-5.

Brantner, A, Grein, E, 1994: Antibacterial activity of plant extracts used externally in traditional medicine. J. Ethnopharmacol. 44:35-40.

Buck, SL, Rosenthal, RA, 1996: A quantitative method to evaluate Neutralizer Toxicity against Acanthamoeba castellanii. Appl. Environ. Microbiol. 62, 9:3521-6.

Chen, EY, 1994: The efficiency of Automated DNA sequencing. In: Automated DNA sequencing and analysis. Adam, D. (ed.), $1^{\text {st }}$ edition, Academic press, San Diego. New York.

Clarke, B, Sinha, A, Parmar, D, Sykakis, E, 2012: Advances in the diagnosis and treatment of Acanthamoeba keratitis. J. Ophthalmol. Article ID 484892, DOI: doi.org/ 10.1155/ 2012/ 484892.

Degerli S, Berk S, Malatyali E, Tepe B 2011: Screening of the in vitro amoebicidal activities of Pastinaca armenea (Fisch. \&C.A.Mey.) and Inula oculuschristi (L.) on Acanthamoeba castellanii cysts and trophozoites. Parasitol. Res. 110, 2:565-70.

Derda, M, Hadaś, E, Thiem, B, 2009: Plant extracts as natural amoebicidal agents. Parasitol Res. 104:705-8.

Duh, P, Yen, G, 1997: Antioxidant Efficacy of Methanolic Extracts of Peanut Hull in Soybean and Peanut oil. J. Am. Oil Chemists' Society 74:745. doi:10.1007/s11746-997-0212-z. 
El-Sayed, N, Ismail, K, Ahmed, S, Hetta, M, 2011: In vitro amoebicidal activity of ethanol extracts of Arachis hypogaea L., Curcuma longa L. and Pancratium maritimum L. on Acanthamoeba castellanii cysts. Parasitol. Res. 110: 198592.

Ezz Eldin, HM, Sarhan, RM, 2014: Cytotoxic effect of organic solvents and surfactant agents on Acanthamoeba castellanii cysts. Parasitol. Res. 113, 5:1949-53.

Ficker, L, Seal, D, Warhurst, D, Wright, P, 1990: Acanthamoeba keratitis: Resistance to medical therapy. Eye 4:835-8.

Garner, A, 1993: Pathogenesis of acanthamoebic keratitis: hypothesis based on ahistological analysis of 30 cases. Br. J. Ophthalmol. 77:36670.

Gatti, S, Rama, P, Matuska, S, Berrilli, F, et al, 2010: Isolation and genotyping of Acanthamoeba strains from corneal infections in Italy. J. Med. Microbiol. 59:1324-30.

Geetha, K, Ramarao, N, Kiran, S, Srilatha, K, Mamatha, P, et al, 2013: An overview on Arachis hypogea plant. Int. J. Pharmaceut. Sci. Res. 4, 12:4508-18.

Goze, I, Alim, A, Dag, S, Tepe, B, Polat, ZA, 2009: In vitro amoebicidal activity of Salvia staminea and Salvia caespitosa on Acanthamoeba castellanii and their cytotoxic potentials on corneal cells. J. Ocul. Pharmacol. Ther. 25, 4: 293-8.

Heredero-Bermejo, I, Copa-Patiño, JL, Soliveri, J, Gómez, R, de la Mata, FJ, et al, 2013: In vitro comparative assessment of different viability assays in Acanthamoeba castellanii and Acanthamoeba polyphaga trophozoites. Parasitol. Res. 112, 12:4087-95.

Hetta, MH, Aly, HF, Ali, NW, 2014: Estimation of resveratrol content in peanut pericarp and its relation to the in vitro inhibitory activity on carbohydrate metabolizing enzymes. Pharmazie 69, 2:92-5.

Houghton, PJ, Raman, A, Houghton, P, 1998: Laboratory Handbook for the Fractionation of Natural Extracts. Springer, Berlin.

Init, I, Lau, YL, Arin Fadzlun, A, Foead, AI, Neilson, RS, et al, 2010: Detection of free living amoebae, Acanthamoeba and Naegleria, in swimming pools, Malaysia. Trop. Biomed. 27, 3: 566-77.

Ishita, C, Kaushik, B, Uday, B, Ranajit, KB, 2004: Turmeric and curcumin: biological actions and medicinal applications. Current Sci. 87, 1:44
$-53$.

Jasim, H, Knox-Cartwright, N, Cook, S, Tole, D, 2012: Increase in Acanthamoeba keratitis may be associated with use of multipurpose contact lens solution. Br. Med. J. 344:Article ID e1246

Kang, L, Heng, W, Yuan, A, Baolin, L, Fang, H, 2010: Resveratrol modulates adipokine expression and improves insulin sensitivity in adipocytes: relative to inhibition of inflammatory responses. Biochimi. 92:789-96.

Kayser, O, Kiderlen, AF, Croft, SL 2003: Natural products as antiparasitic drugs. Parasitol. Res. 90:55-62.

Kim, TP, Thi, NV, Van, PT, Diem, PQ, et al, 2013: Phytochemical constituents and determination of resveratrol from the roots of Arachis hypogea L. Am. J. Plant Sci.4:2351-8.

Koide, T, Nose, M, Ogihara, Y, Yabu, Y, Ohta, N, 2002: Leishmanicidal effect of curcumin in vitro. Biol. Pharm. Bull. 25:131-3.

Marciano-Cabral, F, Cabral, G, 2003: Acanthamoeba spp. as agents of disease in humans. Clin. Microbiol. Rev. 16:273-307.

Müller, L, Thiel, MA, Kipfer-Kauer, AI, Kaufmann, C, 2012: Corneal cross-linking as supplementary treatment option in melting keratitis: A case series. Klin. Monbl. Augenheilkd 229, 4:411-5.

Nepote, V, Grosso, NR, Guzman, CA, 2002: Extraction of antioxidant components from peanut skins. Grasas Y. Aceites 53, 4:391-5.

Obeid, WN, Araújo, R, Vieira, LA, Machado, MAC, 2003: Ceratite bilateral por Acanthamoe$b a$-relato de caso. Arq. Bras. Oftalmol. 66:87680.

Palmas, C, Wakelin, D, Gabriele, F, 1984: Transfer of immunity against Hymenolepis nana in mice with lymphoid cells or serum from infected donors. Parasitol. 89:287-93.

Perez-Santonja, JJ, Kilvington, S, Hughes, R, Tufail, A, Metheson, M, et al, 2003: Persistently culture positive Acanthamoeba keratitis; in vivo resistance and in vitro sensitivity. Ophthalmology 110:1593-600.

Perrine, D, Chenu, JP, Georges, P, Lancelot, JC, Saturnino, C, et al, 1995: Amoebicidal efficiencies of various diamidines against two strains of Acanthamoeba polyphaga. Antimicrob. Agents Chemother. 3:339-42.

Pietta, PG 2000: Flavonoids as antioxidants. J. Nat. Products 63:1035-42.

Polat, Z, Vural, A, Ozan, F, Tepe, B, Özcelik, 
S, et al, 2008: In vitro evaluation of the amoebicidal activity of garlic (Allium sativum) extract on Acanthamoeba castellanii and its cytotoxic potential on corneal cells. J. Ocul. Pharmacol. Ther. 24: 8-14.

Polat, ZA, Tepe, B, Vural, A, 2007: In vitro effectiveness of Thymus sipyleus subsp. Sipyleus var. sipyleus on Acanthamoeba castellanii and its cytotoxic potential on corneal cells. Parasitol. Res. 101:1551-5.

Roongruangchai, K, Kummalue, T, Sookkua, T, Roongruangchai, J, 2010: Comparison of Pouzolzia indica methanolic extract and Virkon against cysts of Acanthamoeba spp. Southeast Asian J. Trop. Med. Publ. Hlth. 41, 4:776-84.

Schroeder, JM, Booton, GC, Hay, J, Niszl, I, Seal, DV, et al, 2001: Use of subgenic 18S ribosomal DNA PCR and sequencing for genus and genotype identification of acanthamoebae from humans with keratitis and from sewage sludge. J. Clin. Microbiol. 39:1903-11.

Shoaib, HM, Muazzam, AG, Mir, A, Jung, S Y, Matin, A, 2013: Evaluation of inhibitory pot- ential of some selective methanolic plants extracts on biological characteristics of Acanthamoeba castellanii using human corneal epithelial cells in vitro. Parasitol. Res. 112, 3:1179-88.

Siddiqui, R, Khan, NA, 2012: Biology and pathogenesis of Acanthamoeba. Parasites and Vectors 5: 6. DOI: 10.1186/1756-3305-5-6.

Sobolev, VS, Khan, SI, Tabanca, NW, Manly, SP, Cutler, SJ, et al, 2011: Biological activity of Peanut (Arachis hypogaea) phytoalexins and selected natural and synthetic stilbenoids. J. Agric. Food Chem. 59:1673-82.

Wagner, H, Bladt, S, 1996: Plant Drug Analysis, 2nd Edition, Springer Verlag, Berlin.

Wang, ML, Gillaspie, AG, Morris, JB, Pittman, RN, Davis, J, et al, 2008: Flavonoid content in different legume germplasm seeds quantified by HPLC. Plant Gen. Res. 6:62-9.

Yazaki, K, Sasaki, K, Tsurumaru, Y, 2009: Prenylation of aromatic compounds, a key diversification of plant secondary metabolites. Phytochemistry 70:1739-45.



Fig. 1: Arachis hypogaea L. pericarp.



Fig. 2: Amaoebicidal effect of Arachis hypogaea L. pericarp, total ethanol and successive extract $n$-hexane, dichloro-methane, ethyl acetate, methanol and resveratrol along study duration on A. astronyxis cysts. 